\title{
A qualitative study on experiences and needs of breast cancer survivors in Karnataka, India
}

\author{
Sushma Marita Dsouza ${ }^{\mathrm{a}}$, Navya Vyas ${ }^{\mathrm{a}, *}$, Prakash Narayanan ${ }^{\mathrm{a}}$, Shradha S. Parsekar ${ }^{\mathrm{b}}$, \\ Manisha Gore ${ }^{\mathrm{c}}$, Krishna Sharan ${ }^{\mathrm{d}}$ \\ a Department of Public Health, Manipal University, Manipal, India \\ b Department of Statistics, Manipal University, Manipal, India \\ ${ }^{\mathrm{c}}$ Faculty of Health and Biomedical Sciences, Symbiosis International University, Pune \\ d Department of Radiotherapy, Shirdi Sai Baba Cancer Hospital and Research Centre, KMC, Manipal, India
}

\section{A R T I C L E I N F O}

\section{Article history:}

Received 13 July 2017

Received in revised form 5 August 2017

Accepted 7 August 2017

Available online 12 August 2017

\section{Keywords:}

Breast cancer survivors

Experiences

Needs

Qualitative study

\begin{abstract}
A B S T R A C T
Background: Breast cancer is the most prevalent cancer among women worldwide and it is found to be increasing. Breast cancer survivors are threatened with various problems due to disease itself or its treatment and might exist for a long period even after treatment. The existing knowledge on experiences and needs among breast cancer survivors in India is very limited. The present study aimed to explore the experiences and needs of breast cancer survivors.

Methods: In the present study qualitative study design was used and 17 breast cancer survivors, post six months of completed cancer treatment were selected using purposive sampling technique. In-depth interviews were conducted, the data was transcribed and translated and codes and theme were developed.

Results: The study explored the needs and experiences of breast cancer survivors. The experiences of breast cancer survivors were as follows; awareness, psychological expressions, spirituality and misconceptions, economic burden, confinement, body image and bashfulness, maintaining secrecy, family support and physical burden. The needs of breast cancer survivors were identified as financial, informational, breast reconstruction surgery, help in household activities, family support, counseling and emotional support.

Conclusion: Recognizing the experiences and needs of the breast cancer survivors by the family members, health care workers, community members and policy makers after the end of treatment is important to facilitate optimal delivery of health care at the community settings to improve the quality of life of breast cancer survivors.
\end{abstract}

(C) 2017 INDIACLEN. Published by Elsevier, a division of RELX India, Pvt. Ltd. All rights reserved.

\section{Introduction}

Breast cancer is the most prevalent cancer among women worldwide ${ }^{1}$ with 1.7 million new breast cancer cases in $2012^{2}$ and is found to be increasing. In India the peak incidence of breast cancer is reported a decade earlier as compared to western countries wherein it is more common in postmenopausal women. ${ }^{3}$ Advancing age, lifestyle changes, genetic, hormonal and environmental factors are associated with breast cancer. ${ }^{4}$ Survival rates of

\footnotetext{
* Corresponding author.

E-mail address: navya.vyas@manipal.edu (N. Vyas).
}

breast cancer are improving due to early detection and advancement in medical care but vary worldwide. ${ }^{2}$ Every second women in India is dying due to breast cancer making the survival rates poor compared to developed countries. ${ }^{5}$

Breast cancer survivors are threatened with various problems due to disease itself or its treatment and might exist for a long period even after treatment. These problems include fatigue, pain, osteoporosis and early menopause; inability to cope with the disease, traumatic stress, distress, depression, fear of recurrence; and family worries, sexual problems and infertility. ${ }^{1,6,7}$ The lack of resources for routine screening and specialists combined with ignorance and lack of knowledge regarding breast cancer in India leads to a late diagnosis and delay in treatment seeking. ${ }^{8}$ Lack of 
access to radiotherapy in developing countries for breast conservation and sentinel lymph node biopsy for minimally invasive axillary staging leave women with the only choice of total mastectomy. This makes women vulnerable to issues of body image, psychological distress, loss of arm mobility and lymphedema. Aforementioned problems can challenge the recovery and affect quality of life (QOL). ${ }^{9}$

The need for information on diagnosis, stage of the disease, source of treatment, treatment options and side-effects were most required by the cancer patients during as well as post treatment. ${ }^{10,11}$ Although breast cancer is most common cancer in women, the existing knowledge on experiences and needs among breast cancer survivors in India is very limited. India is diverse culturally, geographically and health care equity. Once women complete their breast cancer treatment, their contact with healthcare facility might be limited although they might be having some health related issues. As breast cancer is common and increasing in India especially in reproductive age group it is imperative to understand what these women perceive about their needs. This can be well understood by conducting qualitative indepth interviews. In context, the present study was intended to explore the experiences and needs of breast cancer survivors in Udupi district, Karnataka.

\section{Methods}

\subsection{Study design, setting and eligibility criteria for selecting the} participants

The qualitative research design was used to explore the experiences and needs of breast cancer survivors. In-depth interviews were conducted using semi-structured interview guide. The study was conducted in Udupi district from January to June 2017. Breast cancer survivors, post six months of completed cancer treatment were included. The participants were recruited using purposive sampling from Shirdi Sai Baba hospital, Kasturba Medical College (KMC), Manipal and were interviewed at their residence.

\subsection{Data collection methods}

The permission was taken from Medical Superintendent of KMC, Manipal to have access to the records of the patients maintained in the register. Those participants were selected with the help of hospital records. The contact details were obtained and the participants were being contacted over the phone or in-person at hospital (in Medical or Radiotherapy outpatient-department) when they were coming for follow up. After briefing about the study, participants who were willing, convenient time to visit them at home was being asked. All the authors underwent training in qualitative study design prior to study period.

\subsection{Data collation and guide for interview}

A semi-structured interview guide was used to collect the data which included details on socio demographics and domains focusing on experiences and needs of breast cancer survivors. The guide consisted of the following domains such as sociodemographic details, disease condition, treatment, health care, supportive care, post treatment care and psychological health. This guide was developed by referring existing evidence as well consulting the experts in the field. Interviews were conducted in the local language (Kannada) by one of the investigators (SMD) and were audio recorded with prior permission from the participants. In-depth interviews were discontinued at the point
Table 1

Characteristics of the participants.

\begin{tabular}{|c|c|c|}
\hline Variables & & $\mathrm{n}(\%)$ \\
\hline \multirow[t]{3}{*}{ Age } & Range & $38-70$ years \\
\hline & $\leq 50$ & $7(41.2)$ \\
\hline & $>50$ & $10(58.8)$ \\
\hline \multirow[t]{2}{*}{ Religion } & Hindu & $16(94.1)$ \\
\hline & Christian & $1(5.9)$ \\
\hline \multirow[t]{2}{*}{ Marital status } & Married & $15(88.2)$ \\
\hline & Widowed & $2(11.8)$ \\
\hline \multirow[t]{6}{*}{ Literacy status } & No formal education & $3(17.6)$ \\
\hline & Primary & $2(11.8)$ \\
\hline & Secondary & $6(35.3)$ \\
\hline & Intermediate level & $3(17.6)$ \\
\hline & Diploma & $2(11.8)$ \\
\hline & Graduation & $1(5.9)$ \\
\hline \multirow[t]{3}{*}{ Occupation } & House wife & $15(88.2)$ \\
\hline & Teacher & $1(5.9)$ \\
\hline & Receptionist & $1(5.9)$ \\
\hline \multirow[t]{2}{*}{ Residence } & Urban & $7(41.2)$ \\
\hline & Rural & $10(58.8)$ \\
\hline \multirow[t]{3}{*}{ Stages $^{a}$} & Stage 2 & $11(64.7)$ \\
\hline & Stage 3 & $5(29.4)$ \\
\hline & Stage 4 & $1(15.9)$ \\
\hline
\end{tabular}

$\mathrm{n}=$ Number.

a Stages based on TNM grouping (Source: American Joint Committee on (ancer) $)^{12}$.

of data saturation wherein no new information could be obtained based on domains mentioned in the interview guide.

\subsection{Analysis}

The transcripts of the audio recorded interviews were prepared and translated to English. The themes for the analysis were derived through inductive approach based on existing evidence and consulting experts. Manual thematic analysis was carried out. The data were read and re-read thoroughly to develop codes. Codes were incessantly revised by discussing with all the authors. Thereafter, this information was used to frame a comprehensive note of experiences and needs of breast cancer survivors.

\subsection{Ethical consideration}

Ethical clearance for the study was obtained from the Institutional Ethics Committee (IEC), (IEC 903/2016). Participation was voluntary and informed consent was obtained from all the participants after the purpose of the study was explained to them using a participant information sheet. Confidentiality of the data was guaranteed.

\section{Results}

Total 19 breast cancer survivors were contacted of which 17 indepth interviews were conducted. In addition two participants refused to talk. The duration of interviews ranged from 20 to $45 \mathrm{~min}$. Characteristics of participants are provided in Table 1. Themes emerged under experiences and needs of breast cancer survivors are provided below and codes and verbatim of some of the concerned themes are included in Table 2.

\footnotetext{
${ }^{1}$ Balding the head by offering hair to God is one of the custom followed by Hindus at holy places such as Tirupathi. Source: Why Do Hindus Shave Off Their Head? 2014. Available from: https://www.boldsky.com/yoga-spirituality/faith-mysticism/ 2014/why-do-hindus-shave-off-their-head.html.
} 
Table 2

Codes and Verbatim.

\begin{tabular}{|c|c|}
\hline Themes/Subthemes & Codes/Verbatim \\
\hline Post diagnosis reactions & $\begin{array}{c}\text { Suicidal thoughts } \\
\text { 'I tried to commit suicide but couldn't do, because of my children since they were very young and nobody was there to look after them.' } 39 \text { year, NKM }\end{array}$ \\
\hline Fear of disease & $\begin{array}{l}\text { Fear of recurrence } \\
\text { 'I was anxious and scared to go to the hospital and see reports due to fear of recurrence of the disease'. } 45 \text { year, A }\end{array}$ \\
\hline $\begin{array}{l}\text { Spirituality and } \\
\text { misconceptions }\end{array}$ & $\begin{array}{l}\text { Resentment over God } \\
\text { 'Since I got cancer I showed my anger at God. I was not doing prayer.' } 45 \text { year, J } \\
\text { Curse of elderly people } \\
\text { 'I believed that I got disease because of my parents curse as I had gone against their wish to marry a person who was from different cast.' } 45 \text { year, SN }\end{array}$ \\
\hline Economic burden & $\begin{array}{l}\text { Financial difficulty } \\
\text { 'When the matter of money comes I used to fight with the doctor that I don't want the treatment.' } 60 \text { year, } \mathrm{U}\end{array}$ \\
\hline Confinement & $\begin{array}{c}\text { Social restriction } \\
\text { 'I lost all hair. It was like Tirupathi kshwra' (balding the head by offering hair to God at Tirupathi), and everyone would ask so I didn't go anywhere. } \\
\text { We didn't tell anyone that this (breast cancer)has happened.' 70 year, SA }\end{array}$ \\
\hline Family support & $\begin{array}{c}\text { Care from family members } \\
\text { 'I could manage the finances but no one was there to take care of me in cooking, cleaning and accompanying to the hospital.' } 52 \text { year, JD }\end{array}$ \\
\hline Physical burden & $\begin{array}{l}\text { Side effects } \\
\text { 'During chemotherapy I had so much pain, vomiting and something which cannot be explained. That's of no use now if I tell.' } 70 \text { year, SN }\end{array}$ \\
\hline Informational need & $\begin{array}{c}\text { Post treatment care } \\
\text { 'I want to know what food I should eat since I got diabetes along with cancer.' } 45 \text { year, S }\end{array}$ \\
\hline $\begin{array}{l}\text { Breast reconstruction } \\
\text { surgery }\end{array}$ & $\begin{array}{l}\text { Artificial breast implantation } \\
\text { 'Breast cancer patients in abroad undergo artificial breast implantation surgery which is not available in India.' } 70 \text { year, SN }\end{array}$ \\
\hline Help in household activity & $\begin{array}{c}\text { House hold activity } \\
\text { 'When I get tired I feel like someone should be there to do it (work), I feel happy if someone is there to cook and do other things.' } 45 \text { year, SN }\end{array}$ \\
\hline Need for family support & $\begin{array}{l}\text { Accompanying to the hospital } \\
\text { 'I can't go alone to the hospital as it is difficult. Somebody should be there along with me.' } 52 \text { year, JD }\end{array}$ \\
\hline Emotional support & $\begin{array}{l}\text { Emotional feelings } \\
\text { 'I am in this bad condition and no one is there to ask, "how are you?". My sister is also not supporting me. We too have some expectations like } \\
\text { someone should talk to us with love. Money is not everything, good words are more important.' (Participant was crying). 50 year, JD }\end{array}$ \\
\hline
\end{tabular}

\subsection{Experiences}

The major themes emerged under experiences of breast cancer survivors are represented below (Fig. 1).

\subsubsection{Awareness}

There was lack of awareness about the breast cancer symptoms. Due to which early manifestations were ignored leading to delay in health check-ups. Although, local newspaper articles provided information on periodic screening, information on where mammography is conducted was inadequate.

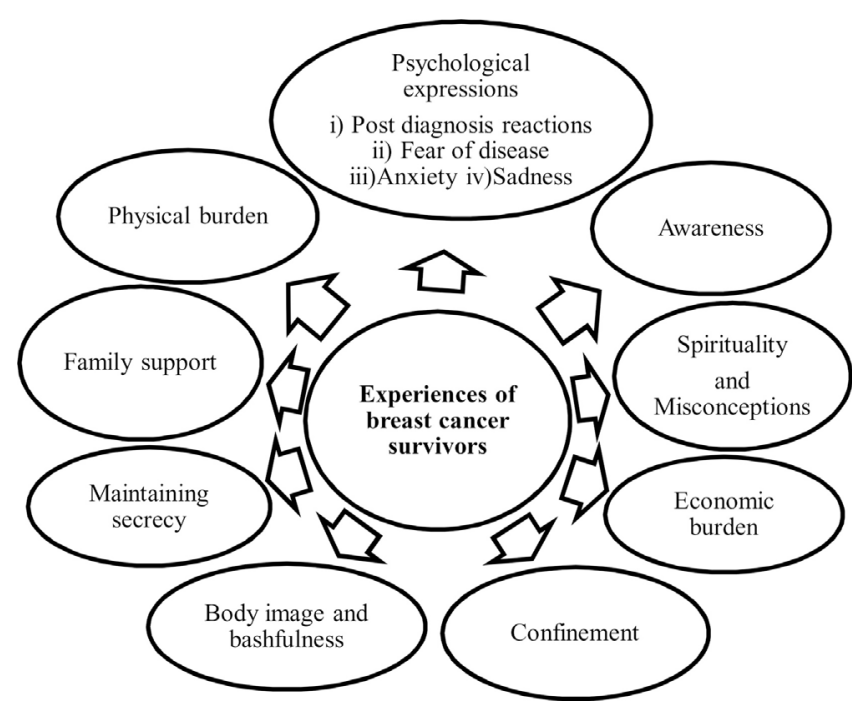

Fig. 1. Experiences of breast cancer survivors.

\subsubsection{Psychological expressions}

3.1.2.1. Post diagnosis reactions. Participants did not accept having cancer but gradually had to. There was difference in perception of shock after the diagnosis. Some perceived being anxious about their future, irritated and apprehensive about health. Hair loss and skin changes had shocked the participants after their first chemotherapy. The mental disturbance led to suicidal thoughts and few tried to commit suicide. Because participants thought that it would be difficult for them to live with the disease and that it was an additional burden (treatment expense, care giving) on family members.

3.1.2.2. Fear of disease. The fear of disease, treatment and recurrence was common. Fear of side-effects lead to refusal in treatment.

3.1.2.3. Anxiety. Cancer was considered as being incurable and expressed with anxiousness related to the disease and its side effects which caused a lot of sufferings to oneself and family.

3.1.2.4. Sadness. Sadness (bejar) was common in all breast cancer survivors. Sadness expressed by crying, deny talking to family members or visitors.

\subsubsection{Spirituality and misconceptions}

God was worshiped after the traumatic experience of getting diagnosed with cancer. At the initial period following diagnosis participants showed resentment on God and God was being blamed. As the disease progressed there was increase in offering prayers and having faith on God. Reading holy books and having positive thoughts on God helped in mindfulness.

Superstitious beliefs pertaining to the cause of cancer came due to the curse of God, curse of elderly people and evil spirits. Participants believed that it was because of curse from elderly people as they (Participants) had gone against their parents wish. It 
was believed that worshiping God could save them from the curse and evil spirits. 'Būta kōla' (impersonation by spirits or deities) was being performed. 'Animal $b \bar{a} l i$ (sacrifice)' was offered to please god and to have mercy.

\subsubsection{Economic burden}

The economic burden was an important and common domain. High costs of treatment increased out of pocket expenditure due to lack of health insurance. The expensive nature of the treatment made participants refuse the treatment and forced to borrow money or take loans from others. Financial burden escalated due to loss of daily wages earned by participants due to missing the work.

\subsubsection{Confinement}

The participants were confined to house during treatment because of discomfort due to people's queries. Besides difficulty in making people understand about their disease and discussion would take it in a different way (cancer is incurable).

\subsubsection{Body image and bashfulness}

Concern about physical appearance, especially hair loss and mastectomy, as it can be noted easily, has led to change in dressing style to adjust with new appearance. Staring at these parts by people was uncomfortable because it caused feeling of shyness as the body part was missing. Therefore, use of cotton to fill the gap after mastectomy and wig for hair loss was being considered.

Breasts were considered as private parts which lead to feeling of shyness to expose the parts in front of male doctors for examination. Bashfulness also restricted participants not to share the symptoms to family members. This feeling delayed treatment/ diagnosis seeking behaviour.

\subsubsection{Maintaining secrecy}

Due to various reasons the participants hide their disease condition: did not want dear ones (family members, relatives and friends) to be depressed after knowing their fatal health condition. Secondly, the risk of developing the cancer among children was more as cancer is hereditary. This in turn causes problem in getting marriage proposals if people come to know that their mother had cancer. Thirdly, people would ask unnecessary questions leading to bad feeling. Fourthly, disheartening feeling due to misconception of cancer being incurable exacerbate the disease condition.

\subsubsection{Family support}

Family support contains financial, psychological, physical and moral support. Although most of the participants received support from their family few did not get any kind of support. Physical support was crucial and viewed as household activities, support while getting up from bed, accompanying hospital.

\subsubsection{Physical burden}

The treatment of cancer leads to body pain, lack of sleep, loss of appetite, vomiting, weight loss and other unexplainable symptoms. These side effects caused difficulty in performing daily activities.

\subsection{Needs}

Themes emerged under needs of breast cancer survivors are represented below (Fig. 2).

\subsubsection{Financial need}

Need for financial expenses during treatment were common among the survivors. Since the cost of treatment was quiet high participants borrowed the money, expressed the need of money to return it back. The expenditure for regular follow up after the

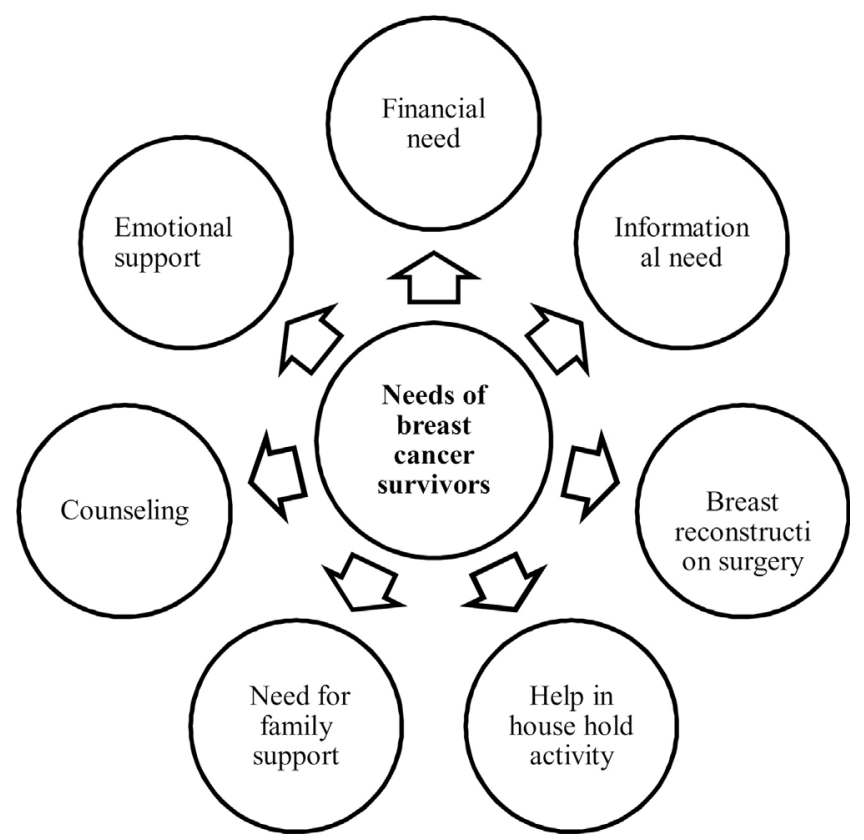

Fig. 2. Needs of breast cancer survivors.

completion of treatment includes travelling, mammography, blood test and food.

\subsubsection{Informational need}

The informational need about post treatment care comprises of diet, exercise and follow-up. Moreover, desire to know the causes of cancer and need of awareness campaign.

\subsubsection{Breast reconstruction surgery}

If artificial breast implantation was done then no one would recognize that mastectomy had been done and this will rule out wearing of cotton pads.

\subsubsection{Help in household activity}

Survivors were not able to perform certain household or daily activities after the completion of treatment. There is a need for help in certain household activities such as cooking, cleaning and washing.

\subsubsection{Need for family support}

Family support (financial, physical, psychological support) is essential for the patients to regain health. Family support such as accompanying to the hospital was needed.

\subsubsection{Counseling}

Counseling in the hospital before any kind of treatment and follow-up for cancer can reinforce to think positively about their recovery from disease. Counseling gives moral support which is important to get cured at the earliest.

\subsubsection{Emotional support}

Emotional support was more about caring with love. It gives mental support for the early recovery. The meaning of emotional support was talking with love, caring, warmth and reassuring which brings out positive feeling about recovery.

\section{Discussion}

The study was conducted to explore the experiences and needs of breast cancer survivors. In-depth interviews brought out 
detailed understanding of beliefs and quality information from the participants. There was dearth of studies among breast cancer survivors in Karnataka, India and this study came out with some interesting findings.

In the study women were unaware of symptoms of breast cancer and ignored it because they had no health problems which delayed health checkup. These findings were unison with the findings of previous studies. ${ }^{13-15}$ Prior knowledge and understanding of breast health helped women to identify changes in their breast and to seek early medical treatment. ${ }^{16}$ Evidence suggests that only one to two fifth breast cancer patients are diagnosed in early stages in India, which worsens the survival rates. ${ }^{17}$

Fear of the disease, treatment and recurrence was expressed by the participants in the study. The fear was expressed due to the fatal nature of the disease and the distress it could cause to the patients. These findings were consistent with the previous studies. ${ }^{11,14}$

Survivors experienced some sadness related to their lost body parts, ${ }^{11}$ mostly during a social event or among other people. ${ }^{18}$ In this study participants were concerned about their body especially the hair loss and mastectomy which led to social restriction. Similar findings were seen in the previous study. ${ }^{19}$ The study revealed that women who were more concerned about their body tried to change their dressing styles in order to adjust with the new appearance. These study findings were consistent with the previous studies. ${ }^{19,20}$

Breast cancer survivors in the study didn't reveal their disease condition to others because they knew that cancer is hereditary and their children might inherit the same. Thus their children had problem in getting marriage alliances. Besides, survivors were concerned about family members feeling of being sad after knowing about their disease condition. These findings were congruent with a previous study. ${ }^{13}$ The women used to hide their disease condition to avoid social rejection, as the disease was considered to be contagious or were stigmatized. ${ }^{21,22}$ These findings were not reported in the present study. So women used to hide their disease condition to avoid social isolation and rejection by the society. This can also affect women's access to information, early detection, and treatment. ${ }^{21}$

Spiritual aspect had an important role especially during treatment phase of breast cancer survivors. The survivors expressed their views about worshipping God after traumatic experience of getting diagnosed with cancer. Survivors had positive thoughts where they believed that God would save them from the disease. Similar findings were identified in the previous studies. ${ }^{11,13,19}$ In the present study survivors believed that they got the disease due to curse of God, curse of elderly people and evil spirits which led to animal sacrifice and offering prayers to God to save them from curse and evil spirits.

The family and friends provided support with strength, courage and motivation to successfully manage and navigate the different stages of treatment and adjustments even after they were told they were cancer free. ${ }^{16}$ Immediate family, were described as providing practical support such as taking participants to hospital appointments, helping with household chores, assisting with tasks such as bathing or brushing their hair, which the women found difficult after surgery, and caring for other family members. ${ }^{11,19}$ In the current study family support included financial, psychological, physical and moral support. Participants in the current study were getting family support but some of them revealed that they lack family support such as financial support, helping in house hold activities, psychological support. These study findings were similar to the findings of the previous studies. ${ }^{23,24}$

Women considered themselves lucky because they did not experience too many financial difficulties because their health insurance covered treatment costs. ${ }^{16}$ Some of the women had financial difficulties due to loss of work due to illness. ${ }^{11,13}$ In the current study women faced financial difficulties as out of pocket expenditure was quite high due to lack of health insurance.
In this study survivors felt the need of information about post treatment care which includes diet, exercise and follow up. Similar findings were found in the previous study. ${ }^{7}$ There was need for information on signs and symptoms of cancer recurrence ${ }^{23}$.

Since finances regarding treatment were major concern of the survivors there was need for information on treatment cost reduction. ${ }^{25}$ Participants had financial needs for their follow up visits to the hospital and post treatment care. They expressed that they refused to take the treatment at the initial phase of the diagnosis due to high cost of the treatment. These findings were similar with the previous study. ${ }^{14}$

Survivors reported that they have received counseling before surgery and treatment but certain services were unavailable which included issues about handling side effects of treatment, getting information about clothes to be worn, gaining access to prosthesis and as an outlet of emotional expression. ${ }^{25}$ However in the current study participants expressed the need for counseling before giving any kind of treatment for breast cancer.

This study considered participants who have completed the cancer treatment similar studies can be planned for women who are under treatment and in different stages. We didn't find breast cancer survivors in early stage (stage 0 and 1 ) due to which their experiences and needs could not be explored. Although qualitative interviews needed very few participants, convincing the participants was challenging as it required expertise.

The study provided insight into the experiences and needs of breast cancer survivors. The participants have undergone traumatic experiences during diagnosis, treatment and post treatment phases. The study findings throw light into the fact that the breast cancer survivors have major felt needs for finance, physical and family support. Recognizing the experiences and needs of the breast cancer survivors by the family members, health care workers, community members and policy makers after the end of treatment is important to facilitate optimal delivery of health care at the community settings to improve the quality of life of breast cancer survivors.

\section{Conflict of interest}

Authors declare no funding and no conflicts of interest.

\section{Acknowledgements}

The authors would like to thank all the breast cancer survivors who participated in this study. We would like to show gratitude to the Department of Public Health, Manipal University, Manipal and Shirdi Sai Baba Cancer Hospital and Research Centre, KMC, Manipal for their support.

\section{References}

1. Abdollahzadeh F, Moradi N, Pakpour V, et al. Un-met supportive care needs of Iranian breast cancer patients. Asian Pac J Cancer Prev. 2014;15(9):3933-3938.

2. Breast Cancer Statistics. World Cancer Research Fund International [Internet]. Wcrf.org. 2017 [cited 3 July 2017]. Available from: http://www.wcrf.org/int/ cancer-facts-figures/data-specific-cancers/breast-cancer-statistics.

3. Kamath R, Mahajan SK, Sanal STA. Study on risk factors of breast among patients attending the tertiary care hospital, in Udupi District. Indian J Community Med. 2013;38(2):95-99.

4. Dossus L, Benusiglio PR. Lobular breast cancer: incidence and genetic and nongenetic risk factors. Breast Cancer Res. 2015;17(37):1-8.

5. Statistics of Breast Cancer in India. [cited 3 July 2017]. Available from: http:// www.breastcancerindia.net/statistics/stat_global.html.

6. Kaur N, Miglani R, Grover RK. Information and rehabilitation needs of Indian breast cancer patients. Report of a cross-sectional study. Indian J Cancer. 2014;51(3):262-266.

7. Cappiello M, Cunningham RS, Knobf MT, Erdos D. Breast cancer survivors information and support after treatment. Clin Nurs Res. 2007:16(4):278-293.

8. Tfayli A, Temraz S, Mrad RA, Shamseddine A. Breast cancer in low and middle income countries: an emerging and challenging epidemic. J. Oncol. 2010;1-5. 
9. Ganz PA, Yip CH, Gralow JR, et al. Supportive care after curative treatment for breast cancer (survivorship care): Resource allocations in low- and middleincome countries. A Breast Health Global Initiative 2013 consensus statement. Breast. 2013;22(5):606-615.

10. Rutten LJF, Arora NK, Bakos AD, Aziz N, Rowland J. Information needs and sources of information among cancer patients: a systematic review of research (1980-2003). Patient Edu Couns. 2005;57:250-261.

11. Ashing-Giwa KT, Padilla G, Tejero J, et al. Understanding the breast cancer experience of women: a qualitative study of African-American, Asian American, Latina and Caucasian cancer survivors. Psych Oncol. 2004;13:408428.

12. American Joint Committee on cancer. [Cited 3 July 2017]. Available from: https://cancerstaging.org/references-tools/quickreferences/Pages/default. aspx.

13. Yusuf A, Hadi ISA, Mahamood Z, Ahmad Z, Keng SL. Understanding the breast cancer experience: a qualitative study of Malaysian women. Asian Pacific J Cancer Prev. 2013;14(6):3689-3698.

14. Norsa B, Rahmah MA, Rampal KG. Understanding barriers to Malaysian women with breast cancer seeking help. Asian Pac J Cancer Prev. 2012;13:3723-3730.

15. Taib NA, Yip C, Low W. Recognising symptoms of breast cancer as a reason for delayed presentation in Asian women-the psycho-socio-cultural model for breast symptom appraisal: opportunities for intervention. Asian Pac J Cancer Prev. 2011;12:1601-1608.

16. Williams F, Jeanetta SC. Lived experiences of breast cancer survivors after diagnosis, treatment and beyond: qualitative study. Understanding Breast Cancer Survivorship. Health Expect. 2015;19:631-642.
17. Ernst and Young LLP. Call for Action: Expanding Cancer Care in India. [Cited 3 July 2017]. Available from: http://www.ey.com/Publication/vwLUAssets/EY-Callfor-action-expanding-cancer-care-in-india/\$FILE/EY-Call-for-actionexpanding-cancer-care-in-india.pdf.

18. Sathiyaseelan RS. A. Experiences of female breast cancer survivors on their appearance related issues impacting their identity. Int J Sci Res Publ. 2013;3 (6):1-7.

19. Patel G, Harcourt D, Rumsey N, Naqvi H. Exploring the lived experience of breast cancer diagnosis and treatment amongst Gujarati speaking Indian women. Divers Equal Health Care. 2015;12(1):9-17.

20. Koçan S, Gürsoy A. Body image of women with Breast cancer after mastectomy: a qualitative research. J Breast Health. 2016;145-150.

21. Errico KM, Rowden D. Experiences of breast cancer survivor-advocates and advocates in countries with limited resources: a shared journey in breast cancer advocacy. Breast J. 2006;12:111-116.

22. Kaur R. Cultural beliefs, cancer and stigma experiences of patients from Punjab (India). Ethno Med. 2015;9(2):247-254.

23. Kwok C, White K. Perceived information needs and social support of ChineseAustralian breast cancer survivor. Support Care Cancer. 2014;22(10):26512659.

24. Yoo GJ, Sudhakar A, Le MN, Levine EG. Exploring coping strategies among young Asian American women breast cancer survivors. J Canc Educ. 2017;32:43-50.

25. Barthakur MS, Sharma MP, Chaturvedi SK, Manjunath SK. Experiences of breast cancer survivors with oncology settings in urban India: qualitative findings. Indian J Surg Oncol. 2016;7(4):392-396. 